\title{
COMPARAÇÃO DO EFLUENTE DE DRENAGEM HIDROPÔNICO DE TOMATE COM MEIO ZARROUK E RAOS PARA CULTIVO DE ARTHROSPIRA PLATENSIS
}

Yan Valdez Santos Rodrigues"; Edna Dos Santos Almeida2; Erika Durão Vieira ${ }^{3}$ Darlan Azevedo Pereira ${ }^{4}$

${ }^{1}$ Centro Universitário SENAI CIMATEC; Salvador-BA; yanvaldez@gmail.com

2, ${ }^{3}$ Química; Centro Universitário SENAI CIMATEC; Salvador-BA;

${ }^{4}$ Engenheiro de Produção; Universidade Federal da Paraíba

Resumo: Existe um grande potencial associado a microrganismos na atualidade como forma alternativa de alimento, porém isso depende das suas condições de crescimento: $\mathrm{pH}$, luz, temperatura e uma solução contendo NPK. Neste trabalho, o objetivo foi comparar um efluente de drenagem de cultivo de hidroponia de tomate com os meios de cultura artificial Zarrouk e Raos para verificar sua viabilidade como meio de cultivo alternativo para a Arthrospira platensis. Realizou-se o cultivo da Arthrospira empregando diferente concentrações: 25\%, 50\%, 75\% e 100\% de efluente avolumado com meio Zarrouk e dois meios de controle (Raos e Zarrouk). Verificou-se que é possível utilizar o efluente de drenagem para cultivo de Arthospira, contudo, quanto maior a concentração, maior a inibição da microalga.

Palavras-Chave: Arthrospira platensis; efluente de drenagem de hidroponia; Meio de cultivo alternativo; meio Zarrouk; Meio Raos.

\section{COMPARISON OF TOMATO HYDROPONIC DRAIN WASTE WITH ZARROUK AND RAOS MEDIUM FOR ARTHROSPIRA PLATENSIS CULTIVE}

\begin{abstract}
There is a great potential associated with microorganisms today as an alternative form of food, but it depends on their growing conditions: $\mathrm{pH}$, light, temperature and a solution containing NPK. In this work, the objective was to compare a drainage effluent from tomato hydroponics cultivation with the artificial culture media Zarrouk and Raos to verify its viability as an alternative cultivation medium for Arthrospira platensis. Arthrospira was cultivated using different concentrations: 0\%, $25 \%, 50 \%, 75 \%$ and $100 \%$ effluent with Zarrouk medium and two control means (Raos and Zarrouk). It was found that it is possible to use the drainage effluent for Arthospira cultivation, however, the higher the concentration, the greater the microalgae inhibition.
\end{abstract}

Keywords: Arthrospira platensis; hydroponics drainage effluent; Alternative cultivation medium; Zarrouk medium; Raos medium. 


\section{INTRODUÇÃO}

As cianobactérias e microalgas são importantes microrganismos que nos últimos anos tem sido focada como novas oportunidades de produção alimentar de baixo custo, biodiesel, síntese de compostos orgânicos de alto valor agregado e dentre outras várias outras possíveis aplicações. Assim sendo, o potencial associado que elas possuem na atualidade depende diretamente do processo de desenvolvimento dessas, ou seja, das suas condições de convenientes de crescimento: pH, luz e temperatura adequados, também, os nutrientes, que em grande parte necessitam de uma solução contendo nitrogênio, fosforo, potássio, alguns sais e metais em menores concentrações que é designada como meio de cultivo. [1,2]

As cianobactérias como a Arthrospira platensis, conhecida como Spirulina, que era classificada como microalga, é uma das espécies de microrganismos que atualmente já possuem uma variedade de aplicações econômicas, como por exemplo, a geração de biomassa para alimentação, produção de produtos de interesse biotecnológico, farmacêutico, industrial e de combustíveis renováveis, além de ser um organismo aprovado para fins alimentícios pelo órgão regulador Anvisa (Agência Nacional de Vigilância Sanitária) [1,2,4]. Apesar dos pontos positivos, os meios de cultivo para seu cultivo necessitam de investimentos financeiros relativamente altos, devido sua composição depender de reagentes de processos industrias, principalmente em relação ao fornecimento de nutrientes e micronutrientes que são amplamente utilizados. $[1,2,4]$

Neste trabalho, o objetivo foi comparar um efluente alternativo de drenagem de cultivo de hidroponia de tomate com os meios de cultura artificial Zarrouk e Raos para verificar sua viabilidade econômica como meio de cultivo alternativo para a Arthrospira platensis. [2,3]

\section{METODOLOGIA}

O estudo trata-se de uma comparação entre o desenvolvimento da cianobactéria no efluente de drenagem de cultivo de hidroponia de tomate com a mesma em um meio artificial Zarrouk em diferentes proporções e também com o meio de controle Raos, tendo por objetivo também validar outro estudo anteriormente feito com efluente de drenagem de alface.[6] Os dados de composição química foram informados por um técnico agrícola que estavam cultivando hortaliças por hidroponia e a composição do meio Zarrouk e Raos forram obtidas da literatura. [2,3] Com os dados foram calculados em relação a massa dos sais utilizados a massa dos principais elementos nutrientes e micronutrientes N, P, K, Mg, S, B, Cu, Mo, Mn, Zn, Fe, Ca, Co, Na. [2,3]

O cultivo da Arthrospira platensis foi feito em concentrações de efluente de drenagem a $25 \%, 50 \%, 75 \%$ e $100 \%$ e avolumado com o meio de cultivo Zarrouk em triplicata, tendo-se como meio de controle uma duplicata de Zarrouk e uma duplicata de Raos. O cultivo for realizado em erlenmeyers de $500 \mathrm{~mL}$ com $300 \mathrm{~mL}$ de meio de cultivo misto (diferentes concentrações anteriores) que foram devidamente esterilizados em autoclave junto a todo material para retirada de amostras, seguidos da inoculação de $10 \mathrm{ml}$ de inóculo. A realização do cultivo foi feita em uma incubadora shaker com agitação e iluminação controladas (média de 441,45 lux). A avaliação do crescimento da cianobactéria foi feita a partir da análise de absorbância com amostras de $10 \mathrm{~mL}$ a $570 \eta$ m (leituras em triplicata tendo como referências os meios formulados antes da 
inoculação da microalga) em um período de 22 dias, retirando-se 12 amostras ao todo no período, em uma capela de fluxo laminar para reduzir a possibilidade de contaminação. Foi verificado o pH das amostras nas três semanas referentes ao estudo, e observado por um microscópio óptico a presença do microrganismo. Depois plotou-se uma curva de crescimento da microalga (C/Co em função dos dias de cultivo).

\section{RESULTADOS E DISCUSSÃO}

As composições do meio de cultivo artificial e do efluente estão dispostas nos Quadros 1. Observando os dados do Quadro 1 percebeu-se uma composição de metais como $\mathrm{Cu}, \mathrm{Mn}$, Mo mais concentrada e maiores concentrações de NPK no efluente do que no meio Zarrouk, assim como, a presença de $\mathrm{Co}, \mathrm{Na}$ e $\mathrm{Cl}$ apenas no meio artificial.

O efluente teve parte dos nutrientes absorvidos pelas hortaliças do cultivo hidropônico, contudo, segundo o técnico que realiza o cultivo hidropônico, a reposição é feita toda vez que há uma redução da condutividade em relação ao meio inicial formulado para o cultivo. Desta forma, nesse empregou-se uma amostra em que a condutividade elétrica era $2500 \mathrm{mS}$ (micro Siemens). Cabe salientar que a concentração de determinados metais pode ser maior ou menor no efluente de drenagem do que consta no Quadro 1 em função da variação da assimilação dos nutrientes pelas hortaliças. De todo modo, percebe-se uma concentração de metais, seja Cobre, Manganês ou Molibdênio bastante elevados quando comparado ao meio Zarrouk como pode se observar na coluna de razoes no Quadro 1. A Figura 1 e 2 mostra o crescimento da Arthrospira platensis no teste realizado em um ciclo de 22 dias.

Quadro 1 - Composição química do meio Zarrouk [1,2] e do efluente de drenagem de hidropônica

\begin{tabular}{|c|c|c|c|c|}
\hline \multirow{2}{*}{ Espécie } & $\begin{array}{c}\text { Composição } \\
\text { química do } \\
\text { efluente }\end{array}$ & $\begin{array}{c}\text { Composição } \\
\text { química do } \\
\text { Zarrouk }\end{array}$ & $\begin{array}{c}\text { Composição } \\
\text { química do } \\
\text { Raos }\end{array}$ & $\begin{array}{c}\text { Razão entre } \\
\text { efluente e } \\
\text { Zarrouk }\end{array}$ \\
\cline { 2 - 5 } & \multicolumn{4}{|c|}{$\mathrm{g} / \mathrm{L}$} \\
\hline $\mathrm{N}$ & 0,0777 & 0,1065 & 0,4117 & 0,73 \\
\hline $\mathrm{P}$ & 0,0306 & 0,0133 & 0,1139 & 2,26 \\
\hline $\mathrm{K}$ & 0,1590 & 0,3237 & 0,4120 & 0,49 \\
\hline $\mathrm{Ca}$ & 0,0263 & $7,8912 \mathrm{E}-03$ & $2,8829 \mathrm{E}-03$ & 3,34 \\
\hline $\mathrm{S}$ & 0,0446 & 0,0110 & 0,1208 & 4,04 \\
\hline $\mathrm{Mg}$ & 0,0339 & 0,0073 & $8,0758 \mathrm{E}-03$ & 4,60 \\
\hline $\mathrm{B}$ & 0,0192 & $9,9738 \mathrm{E}-04$ & 0 & 19,25 \\
\hline $\mathrm{Cu}$ & 0,0032 & $3,9929 \mathrm{E}-05$ & 0 & 80,14 \\
\hline
\end{tabular}






Figura 1: llustração do cultivo em meio Zarrouk, Raos e efluente de hidroponia, a esquerda os meios de controle Zarrouk e Raos, A direita, $25 \% ; 50 \% ; 75 \% ; 100 \%$ de efluente diluído em meio Zarrouk, após a inoculação no primeiro dia 1 dia de cultivo.
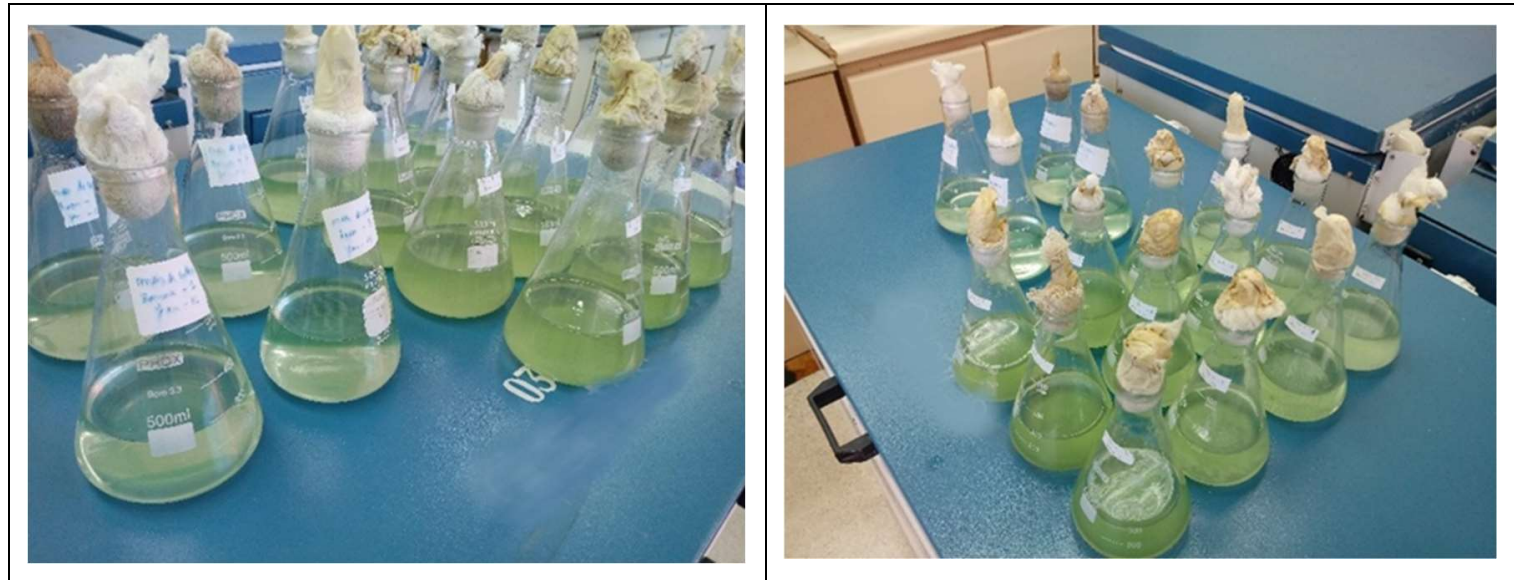

Figura 2: Ilustração do cultivo em meio Zarrouk, Raos e efluente de hidroponia, da esquerda para a direita, Raos, Zarrouk 100\%; 75\%; 50\%; 25\% de efluente, após 22 dias de cultivo.
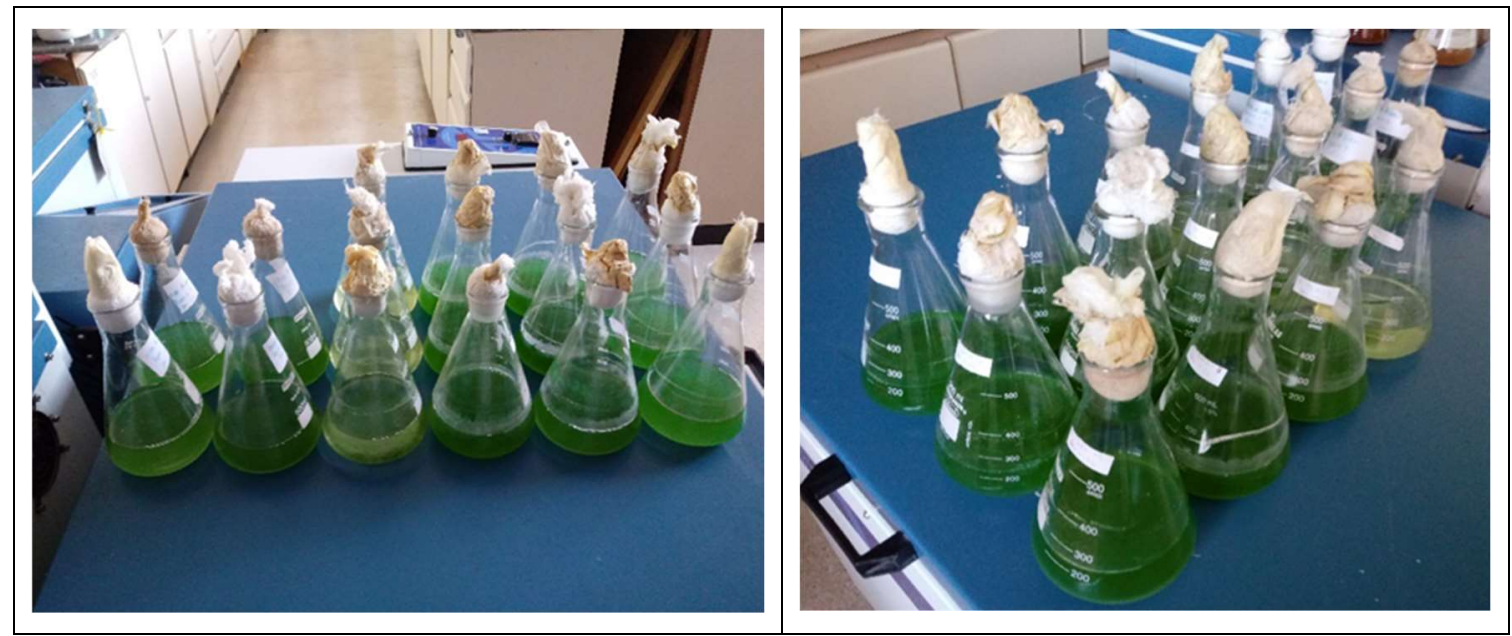

Percebeu-se um gradiente de crescimento nas concentrações de $100 \%, 75 \%, 5$ $0 \%, 25 \%$ do efluente quando comparando os meios de controle, conforme observado na Figura 3 e 4, e também comprovado essa hipótese com a curva de crescimento do Gráfico 1, que mostra um crescimento dependente da concentração de efluente na 


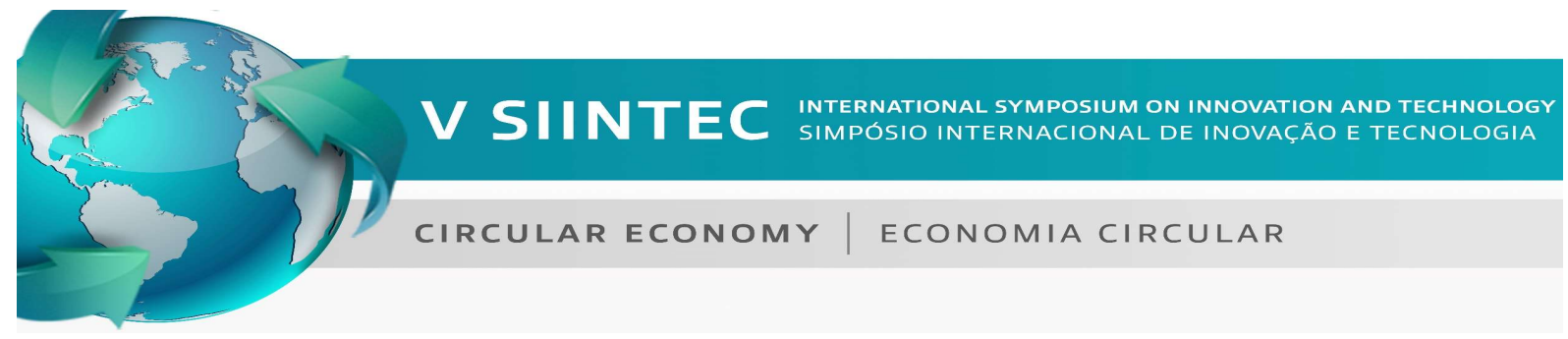

composição, sendo possível verificar a composição de $50 \%$ apresentou o melhor resultado que os meios de controle no mesmo período. O mesmo ocorreu com menor intensidade na composição de $75 \%$. Essa redução provavelmente deveu-se a uma inibição do desenvolvimento da cianobactéria nestas soluções. Dessa forma, levantou-se uma hipótese sobre uma relação entre o excesso de metais do Quadro 1 e o gradiente de crescimento nas concentrações de $0 \%, 25 \%, 50 \%, 75 \%$ do efluente de Hidroponia/Meio Zarrouk já observada em outro estudo.

Figura 3: meio Zarrouk e Raos após 22 dias de cultivo.

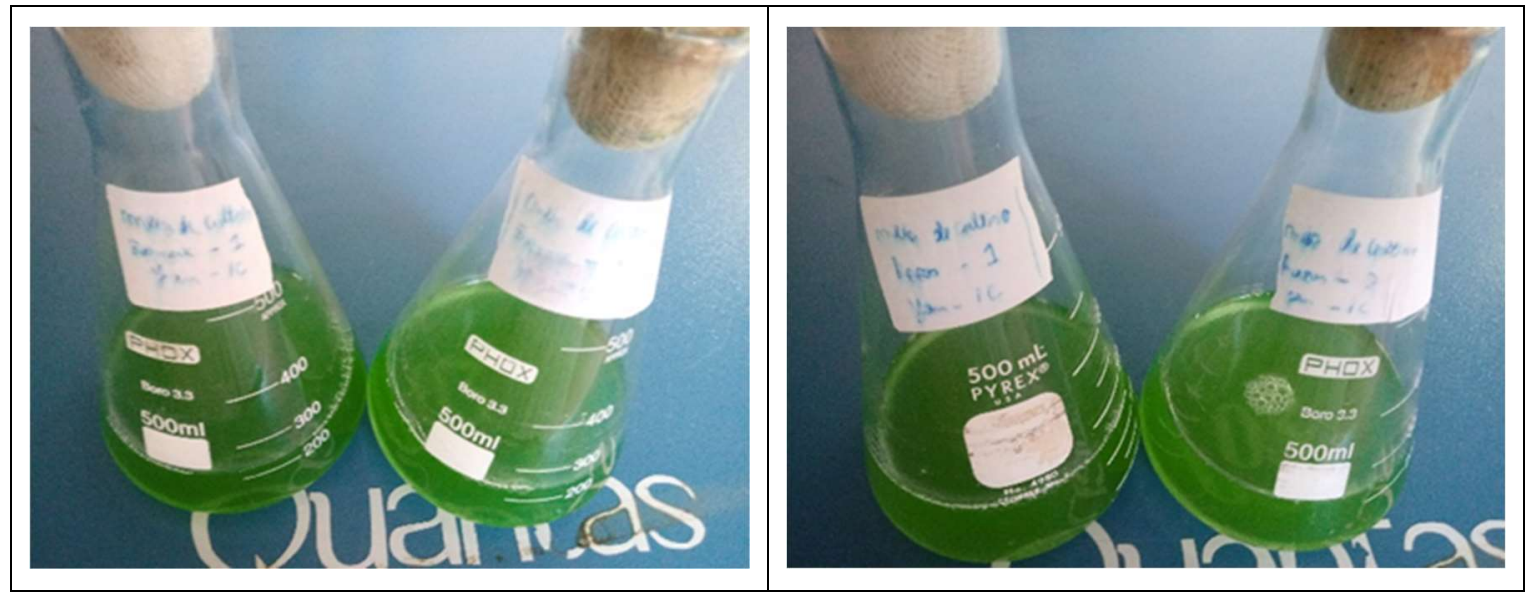

Figura 4: Gradiente de crescimento nas concentrações de 100\%, 75\%, 50\%, 25\% após 22 dias de cultivo.

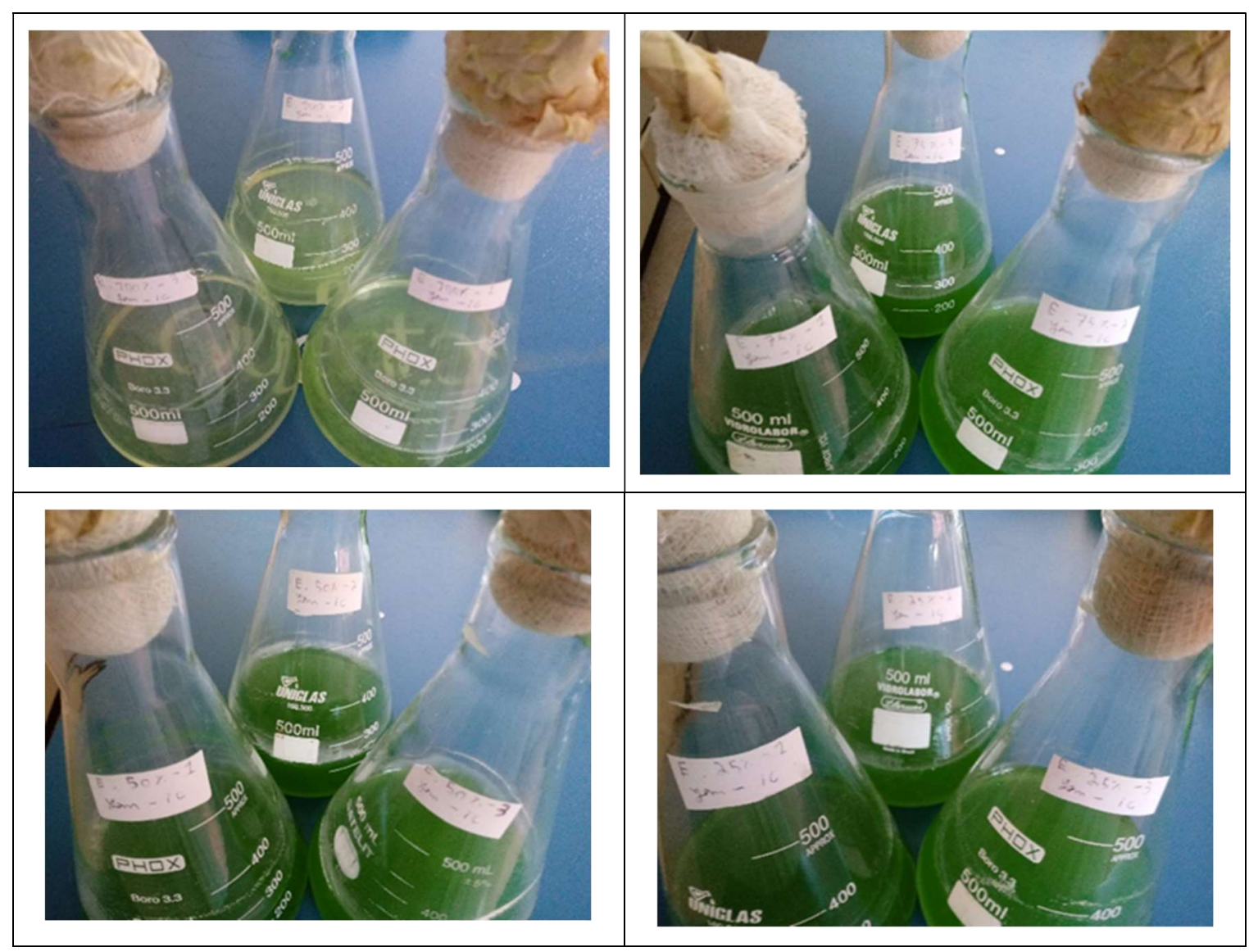


Também se observou, na concentração de $100 \%$ de efluente, mudanças no $\mathrm{pH}$ que começou em 6,0 e passou a atingir 7,9 (todas as outras concentrações apresentaram $\mathrm{pH}$ de 9,8 devido a uma solução tampão presente no meio Zarrouk) além de sedimentação de biomassa no erlenmeyer (Figura 5 ), porém através do microscópio pode se observar sua presença (Figura 6).

Figura 5: Sedimentação de biomassa de cianobactéria nas concentrações de 100\% após 22 dias de cultivo.

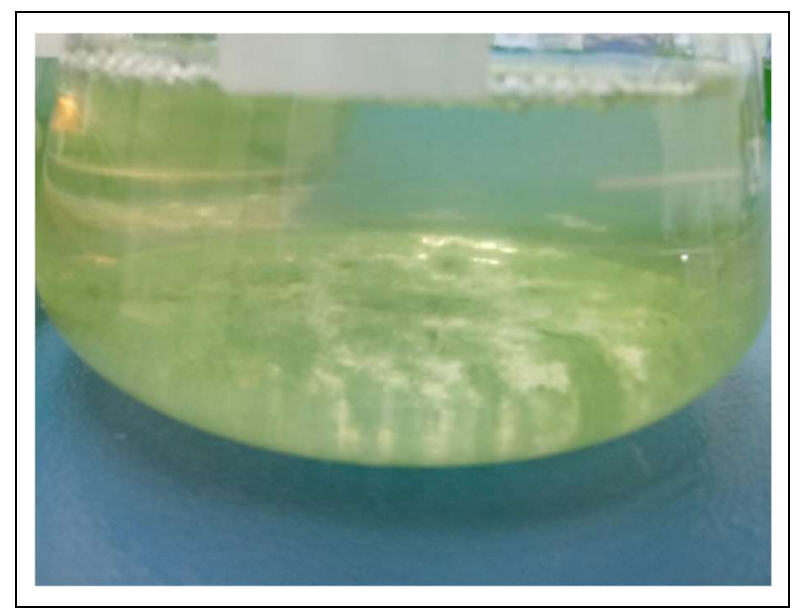

Figura 6: Observa-as sua presença nas concentrações de 100\% após 22 dias de cultivo mesmo após a sedimentação de massa morta.

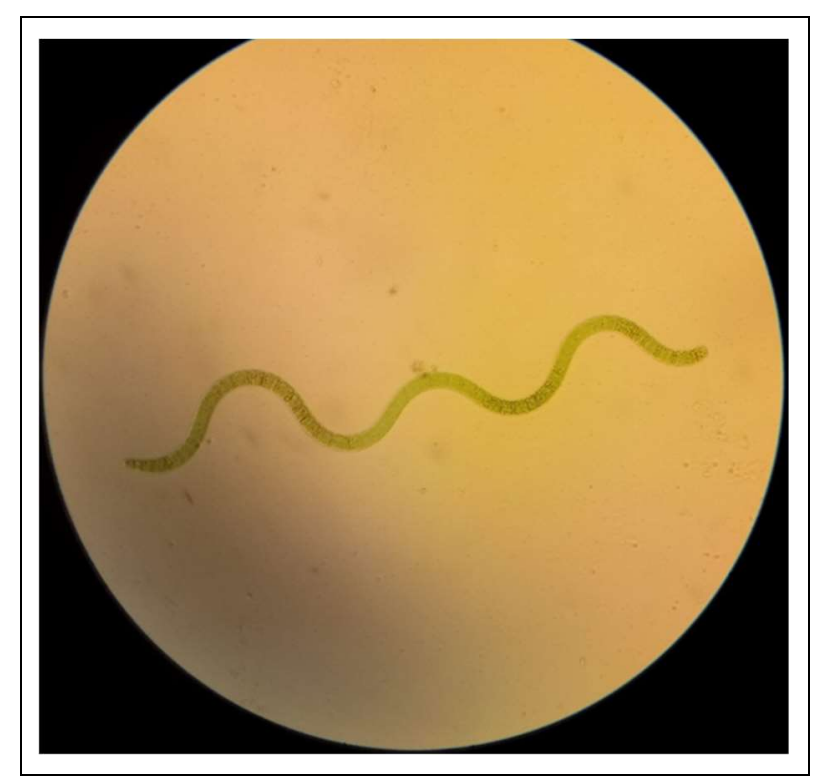

A hipótese da inibição do crescimento pode ser comprovada por outra pesquisa em que o autor relata que "...Embora metais como ferro e cobre sejam necessário para o crescimento de cianobactérias, pois desempenha funções metabólicas essenciais, em altas concentrações pode ser prejudicial ao crescimento das 
cianobactérias já que o excesso leva a reações paralelas que retardam seu desenvolvimento..."[4].

Gráfico 1: Curva de crescimento da cianobactéria em cultivo com variações de concentração de efluente de $25 \% ; 50 \% ; 75 \% ; 100 \%$ de efluente e meios de controle Raos e Zarrouk.

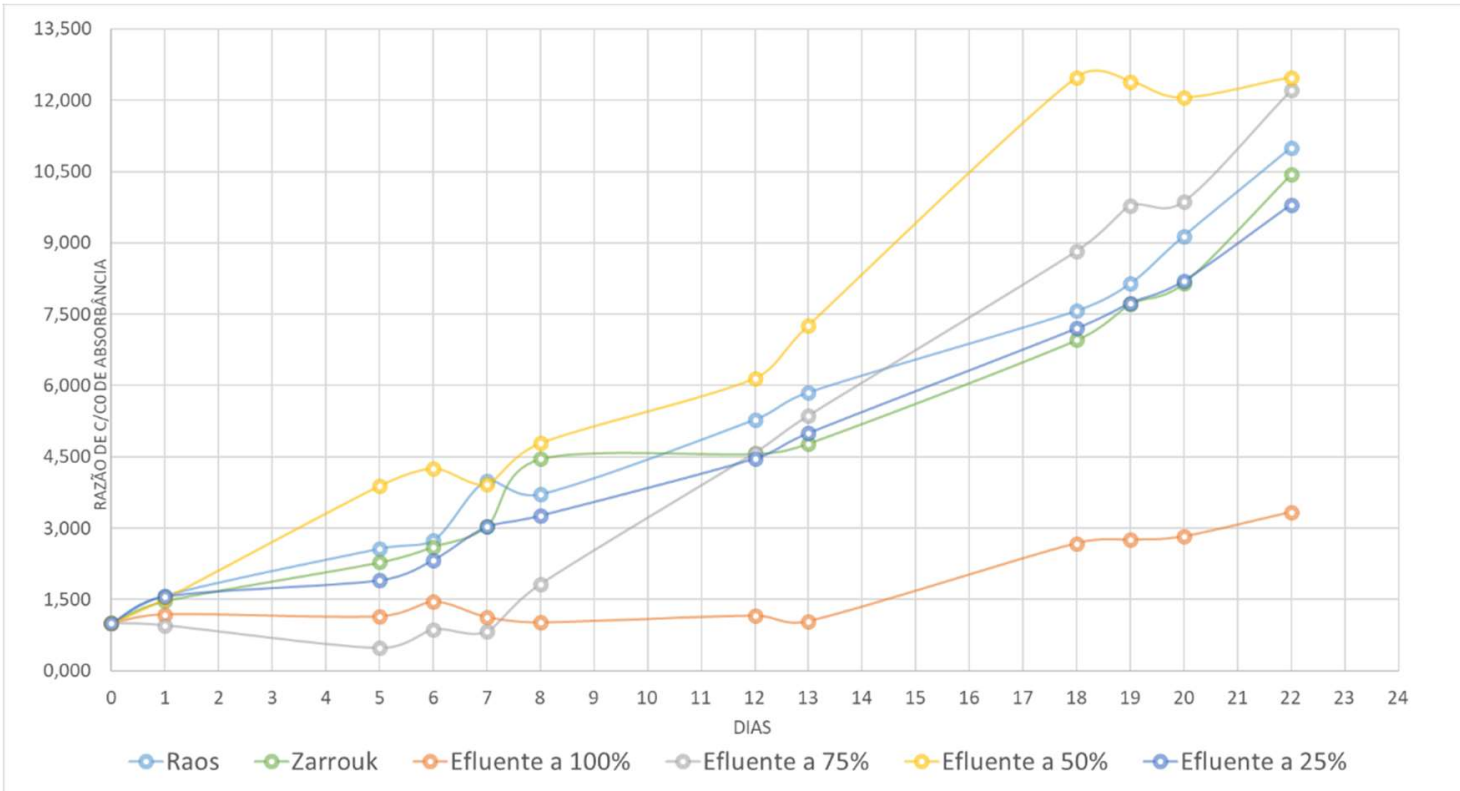

\section{CONCLUSÃO}

Ao final do estudo foi possível perceber uma inibição do crescimento da microalga à medida que a concentração do efluente de drenagem aumenta, de forma que, a cianobactéria teve o menor crescimento na concentração de $100 \%$ de efluente, um maior crescimento nas concentrações de $50 \%$ e $75 \%$ em relação ao cultivo dos meios de controle Raos e Zarrouk e que o meio de controle Raos teve resultados melhores que o meio de controle Zarrouk. Desse modo, a inibição provavelmente é causada devido as grandes concentrações de metais como cobre no efluente e em alguns casos o crescimento demostrou-se maior provavelmente devido a grande quantidade de NPK disponível para o desenvolvimento da cianobactéria em comparação aos meios de controle.

Esse estudo indicou ser possível utilizar como meio de cultivo o efluente de drenagem hidropônica para o crescimento da cianobactéria Arthrospira platensis, contanto que diluído em um meio artificial para equilibrar o excesso de metais.

Em continuidade a esse estudo deve-se verificar a viabilidade do efluente agora diluído em meio Raos e em água para identificar a possibilidade de crescimento da Arthrospira platensis em outras condições, para assim encontrar um meio alternativo adequado.

\section{Agradecimentos}

Agradecemos a instituição fomentadora FAPESB pela bolsa concedida no âmbito do projeto "PRODUÇÃO DE MICROALGAS PARA FINS ALIMENTICIOS 
EMPREGANDO EFLUENTE DE HIDROPONIA DE CULTIVO DE TOMATE”, o qual foi aprovado no pedido $N^{\circ} 3497 / 2019$. Agradecemos ainda à a instituição de ensino Centro Universitário SENAI CIMATEC e aos provedores da amostra de efluente de drenagem e das informações do cultivo hidropônico Fernando Amorim e Lucas Rocha.

\section{REFERÊNCIAS}

1. DERNERET, R. B., Et al., Microalgae, products and applications. Ciência Rural, Santa Maria, v.36, n.6, p.1959-1967, nov-dez, 2006.

2. CALIXTO, C. D., Potencial de Microalgas Regionais Cultivadas em Meios Alternativos para Produção De Biodiesel, Tese de Doutorado, Universidade Federal da Paraíba, 2016.

3. ZARROUK, C. Contribution a l'etuded'unecyanophycee: influence de divers facteurs physiques etchimiquessur la croissance et la photosynthese de Spirulina maxima (Setch et Gardner) Geitler. Theises. Faculty of Science.Universite des Paris; 1966.

4. COSTA, M. H. Cultivo de microalgas em efluente da piscicultura visando a obtenção de biomassa com potencial proteico para aplicação em ração animal. TCC. Universidade Federal da Paraíba Centro de Tecnologia Departamento de Engenharia Química; 2018.

5. MOSTAFA, M. S. et al., Characterization of the iron-containing superoxide dismutase and its response to stress in cyanobacterium Spirulina (Arthrospira) platensis. University of Manitoba, canada; 2014.

6. RODRIGUES, Y. V. S. et al., Comparação do efluente de drenagem hidropônico com meio Zarrouk para cultivo de Arthrospira platensis. Senai Cimatec, Brasil, 2018 